\title{
Primary Health Care as a Foundation for Strengthening Health Systems in Low- and Middle-Income Countries
}

\author{
Asaf Bitton, MD MPH', 2, Hannah L. Ratcliffe, MSc' ${ }^{7}$, Jeremy H. Veillard, PhD ${ }^{3}$, Daniel H. Kress, $P h D^{4}$, \\ Shannon Barkley, MD, MPH $H^{5}$, Meredith Kimball, MSPH', Federica Secci, PhD ${ }^{3}$, Ethan Wong, MPA ${ }^{4}$, \\ Lopa Basu, DO, MPH, MBA ${ }^{5}$, Chelsea Taylor, PhD' , Jaime Bayona, MD, MPH', \\ Hong Wang, MD, $P h D^{4}$, Gina Lagomarsino, $M B A^{6}$, and Lisa R. Hirschhorn, MD MPH ${ }^{1,2}$
}

\begin{abstract}
'Ariadne Labs, Brigham and Women's Hospital and the Harvard T.H. Chan School of Public Health, Boston, MA, USA; ${ }^{2}$ Harvard Medical School, Boston, MA, USA; ${ }^{3}$ The World Bank Group, Washington, DC, USA; ${ }^{4}$ The Bill \& Melinda Gates Foundation, Seattle, WA, USA; ${ }^{5}$ World Health Organization, Geneva, Switzerland; ${ }^{6}$ Results for Development Institute, Washington, DC, USA.
\end{abstract}

Primary health care (PHC) has been recognized as a core component of effective health systems since the early part of the twentieth century. However, despite notable progress, there remains a large gap between what individuals and communities need, and the quality and effectiveness of care delivered. The Primary Health Care Performance Initiative (PHCPI) was established by an international consortium to catalyze improvements in PHC delivery and outcomes in low- and middle-income countries through better measurement and sharing of effective models and practices. PHCPI has developed a framework to illustrate the relationship between key financing, workforce, and supply inputs, and core primary health care functions of first-contact accessibility, comprehensiveness, coordination, continuity, and person-centeredness. The framework provides guidance for more effective assessment of current strengths and gaps in PHC delivery through a core set of 25 key indicators ("Vital Signs"). Emerging best practices that foster high-performing PHC system development are being codified and shared around low- and high-income countries. These measurement and improvement approaches provide countries and implementers with tools to assess the current state of their PHC delivery system and to identify where crosscountry learning can accelerate improvements in $\mathrm{PHC}$ quality and effectiveness.

KEY WORDS: global health; primary care; health policy; measurement. J Gen Intern Med 32(5):566-71

DOI: $10.1007 / \mathrm{s} 11606-016-3898-5$

(c) The Author(s) 2016. This article is published with open access at Springerlink.com

\section{INTRODUCTION}

In 1920, the British government commissioned a report to suggest ways to structure their expanding health system investments. The commission chairman, Lord Bertrand Dawson, borrowing from previous experience in education, proposed three hierarchical levels of care locations (primary,

Received August 17, 2016

Revised September 26, 2016

Accepted September 30, 2016

Published online December 9, 2016 secondary, tertiary). He and the commission first identified "primary care" as the most basic level of a structured health system (akin to primary or elementary education), concerned with caring for simple, common problems in outpatient settings (Fig. 1). ${ }^{1}$

Since that time, a profound evolution has occurred toward understanding the central role of primary health care (PHC) in ensuring individual and population health, transforming PHC from responsibility for the lowestlevel basic tasks toward becoming the heart of an integrated, people-centered system of care. The development of community-oriented primary care in South Africa, India, and the US in the mid-twentieth century showed the early potential of strong PHC systems to produce promising population health results, but these vanguard programs were not met with uniform support for a common conceptual understanding or even shared definition of PHC. Competing notions varied from quite broad definitions of primary health care for all in the Alma-Ata Declaration of 1978 , to the narrower definitions of selective primary care that followed in the 1980 s, designed to address major causes of death in lower-resource settings at that time. ${ }^{1,2}$

With converging forces including broader population demand for higher-quality services, rising health costs, and emergence of non-communicable diseases, health system leaders across the globe are increasingly recognizing the central importance of strengthening PHC to meet these evolving needs (Fig. 1). ${ }^{3}$ This is particularly true in lowand middle-income countries (LMIC) in the midst of providing care for the "double burden" of communicable and non-communicable disease, while transitioning from external donor assistance to sustainable domestic funding. However, a common understanding of how strong PHC systems are produced, and how to iteratively improve them, remains elusive. In this perspective, we introduce a framework designed to better understand if and how PHC is working in LMIC, and where lessons can be learned and spread globally. 


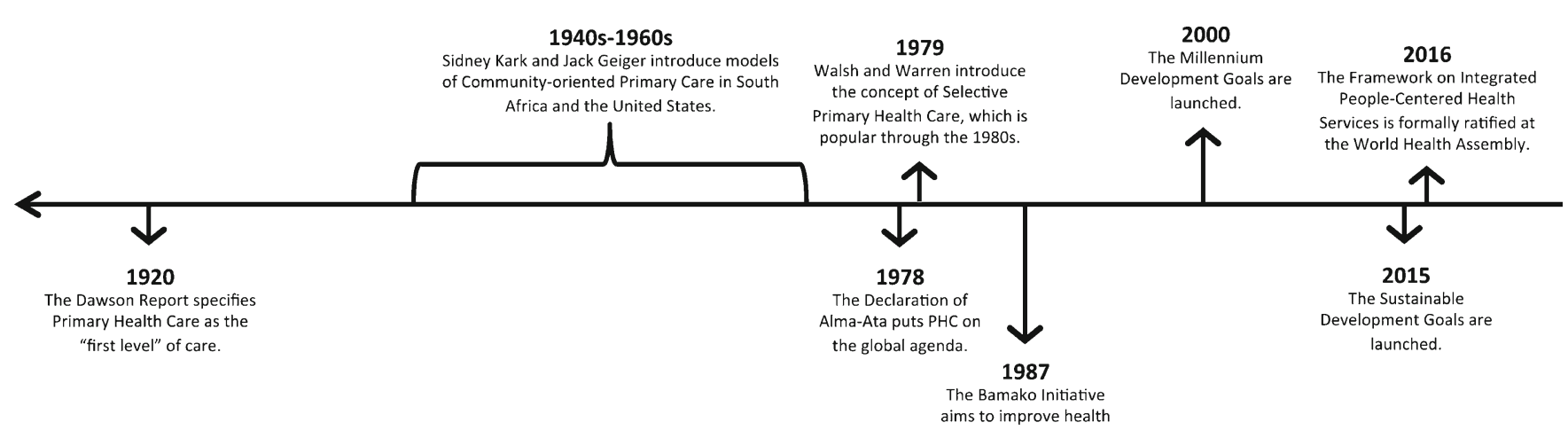

Figure 1 Primary health care evolution over the past century.

\section{TARGETING DISEASES, NOT PEOPLE}

Seeking to capitalize on the influx of global health funding, in 2000, 189 countries ratified the Millennium Development Goals, initiating an unprecedented global effort to promote health and well-being across LMIC, largely through "vertical" programs focused on specific disease or care delivery areas. Since the conclusion of the Millennium Development Goals in 2015 , it has become clear that this effort led to tremendous gains in health: over 15 years, deaths in children under 5 years of age declined by more than $50 \%$, maternal mortality dropped by $45 \%$, new HIV infections fell by $40 \%$, and over 6.2 million malaria-related deaths were prevented. ${ }^{4}$ Despite this remarkable progress, unacceptable gaps in health outcomes and patient needs remain. Every day there are still 16,000 deaths among children under 5, and 830 women die from preventable causes related to pregnancy and childbirth. ${ }^{4}$ 5 The Millennium Development Goals' vertical approach toward healthcare has, in many countries, created fragmented, inefficient, often parallel health systems focused on treating specific diseases rather than promoting holistic health and well-being.

\section{GOING BEYOND VERTICAL PROGRAMS, AND PRIORITIZING USER-CENTERED APPROACHES}

To build upon the successes of the Millennium Development Goals, in 2015, 193 countries adopted the Sustainable Development Goals, to define the next iteration of worldwide development targets for the year $2030 .^{6}$ The health-related Sustainable Development Goal is to achieve universal health coverage, defined as "financial risk protection, access to quality essential health-care services and access to safe, effective, quality and affordable essential medicines and vaccines for all." 4 Strong PHC is the foundation of efficient, equitable, and resilient health systems, and can address the majority of care needs for the majority of people, regardless of where they live. $^{7,} 8$ Achieving quality universal health coverage in a sustainable way will require moving beyond vertical programming, toward integrated health systems, in large part by prioritizing primary health care. ${ }^{7-9}$

\section{HOW BIG IS THE GAP?}

Unfortunately, in many LMIC, PHC capacity is lacking, and health outcomes are poor. Across the world, these gaps are being exposed and exacerbated by the increasing burden of non-communicable diseases and concomitant increases in care complexity. ${ }^{10}$ Acute threats also put a spotlight on weak PHC systems, as was apparent during the 2014 Ebola outbreak in West Africa. The crisis highlighted not only the severe shortage of healthcare infrastructure, human resources, and essential supplies in affected countries, but also poor access to and low quality of care, and a consequent lack of trust and connection between systems and the populations they serve. ${ }^{10}$

Even in the absence of acute threats, recent illustrative studies on the quality of routine PHC in LMIC show that it is far from adequate, with wide variation between and within regions. ${ }^{11}$ A large study in northern India found that providers on average spent $3.6 \mathrm{~min}$ with a patient, completing only onethird of recommended history and physical exams. Diagnoses were provided in only $36 \%$ of cases, and only $12 \%$ of these were correct. Harmful or unnecessary treatments were more common than correct ones (42\% vs. $30 \%$ ). ${ }^{12}$ Similarly poor results were found in Tanzania, Paraguay, and Indonesia. ${ }^{11}$ In China, clinicians completed only $18 \%$ of items on a recommended checklist, provided a correct diagnosis in just $26 \%$ of patients, and dispensed unnecessary or harmful medications in nearly $70 \%$ of interactions. ${ }^{13}$ In Afghanistan, direct observations revealed gaps not just in technical quality, but also communication and time spent with patients. ${ }^{14}$ The underlying causes of these gaps encompass a range of factors, including inadequate training, low effort, misaligned incentives, poor motivation, and unavailability of supplies. ${ }^{12}$

\section{BETTER PHC THROUGH BETTER UNDERSTANDING, MEASUREMENT, AND IMPROVEMENT}

In 2015, the World Health Organization, The World Bank Group, and the Bill \& Melinda Gates Foundation - in partnership with Ariadne Labs and Results for Developmen$\mathrm{t}$-launched the Primary Health Care Performance Initiative (PHCPI), to catalyze improvements in PHC in LMIC through better measurement and sharing of effective practices. ${ }^{3} \mathrm{PHCPI}$ 
activities are derived from a Conceptual Framework for PHC in LMIC (Fig. 2). This framework describes the components necessary for building strong PHC systems, informs better assessment, and identifies modifiable gaps in performance.

\section{A CONCEPTUAL FRAMEWORK FOR GLOBAL PHC: BUILDING ON WHAT WE KNOW WORKS IN THE TWENTY-FIRST CENTURY}

The PHCPI framework was developed through an extensive literature review, global stakeholder consultations with leading experts, advocates, and policymakers, and a review of over 40 existing health systems frameworks. ${ }^{15}$ This process revealed that most frameworks used in LMIC prioritize health systems inputs such as funds, human resources, supplies, facilities, and information systems, with less attention to the interactions between providers, families, communities, and patients and the quality of services they provide and receive.

Building off of widely known frameworks, ${ }^{16-19}$ the PHCPI framework offers a stronger emphasis on people- and community-centered care, supply and demand functions, and integrated service delivery through effective organization and management. The PHCPI framework focuses not just on the traditional system inputs needed to achieve good health outcomes, but also on identifying and mapping the key functions of service delivery that underlie outcome achievement.

The heart of the framework is the Service Delivery domain that captures the interaction of systems and supplies with providers and patients at the moment of care delivery. The first two sub-domains describe aspects of population health management such as local priority setting, community engagement, empanelment, and proactive outreach, as well as teambased organization, facility management capability, information system use, and performance measurement. Together, these sub-domains create the pre-conditions for whether patients have meaningful financial and geographic access to timely care (sub-domain 3 ) and whether competent and motivated providers are present to deliver safe, respectful care (sub-domain 4). The fifth sub-domain-high-quality PHC - includes the classic primary health care functions described by Barbara Starfield and others, including first-contact accessibility, comprehensiveness, coordination, and continui$t y .{ }^{20}$ In addition, the person-centeredness function captures important and often lacking interpersonal and relational dimensions of primary health care, including trust, respect, communication, and improved patient self-management and activation.

The successful combination of systems, inputs, and service delivery contribute to PHC Outputs. Importantly, this domain is focused not just on crude coverage of services, but on effective coverage of high-quality services focused on both prevention and treatment. The final domain, Outcomes, is influenced by all preceding domains. Drawing from the Universal Health Coverage Monitoring Framework ${ }^{21}$ and the Global Reference List of 100 Core Health Indicators, ${ }^{22}$ the domain is focused on morbidity and mortality, as well as key outcomes of people-centered care such as responsiveness to

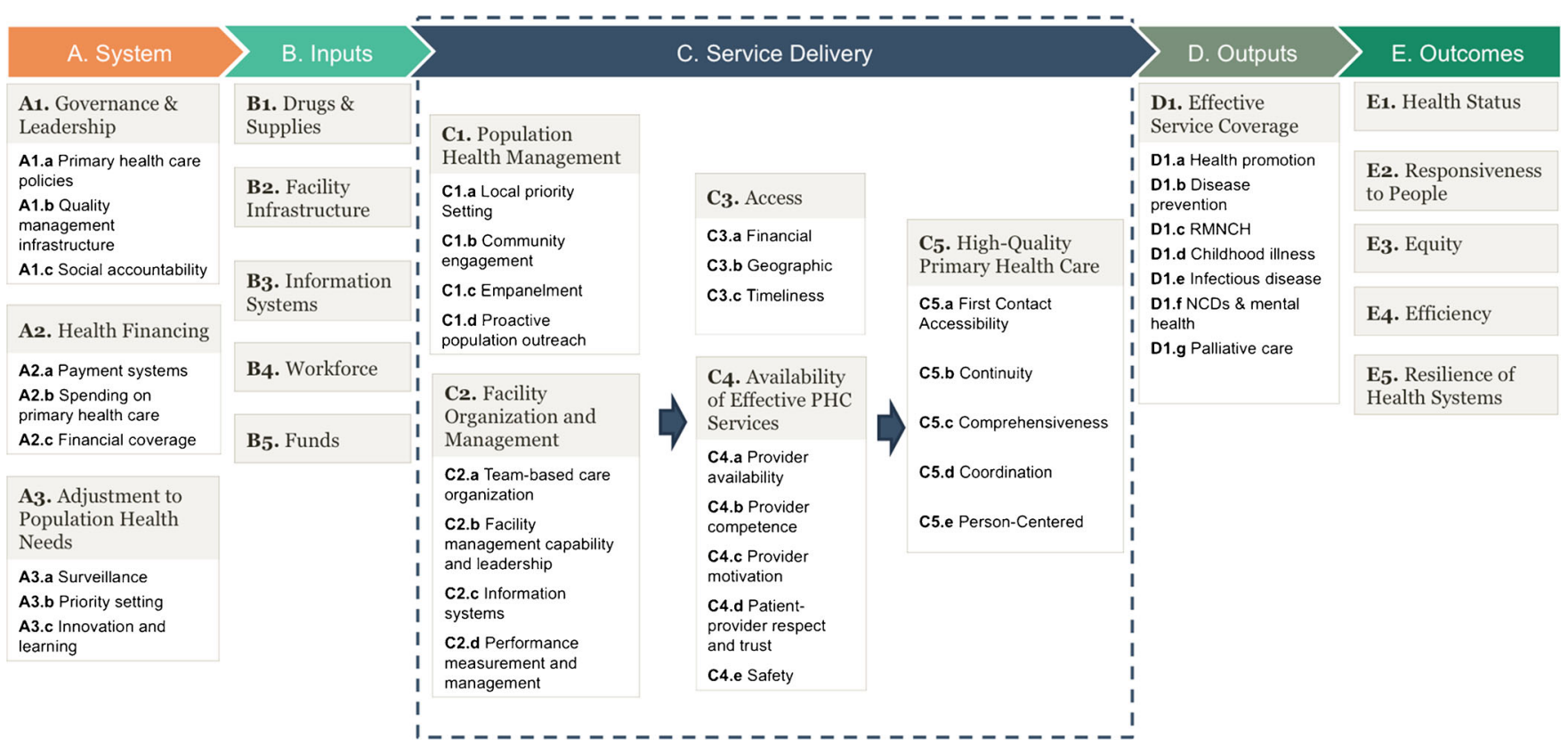

Figure 2 The Primary Health Care Performance Initiative Conceptual Framework. Key terms: Surveillance: the capacity of health systems to identify new and emerging health-related threats; population health: "the health outcomes of a group of individuals, including the distribution of such outcomes within the group" ${ }^{27}$; empanelment: the process by which all patients in a given facility and/or geographic area are assigned to a primary care provider or care team; community engagement: "involving communities in decision-making and in the planning, design, governance and delivery of health care services" ${ }^{28}$; resilience: "the capacity of health actors, institutions, and populations to prepare for and effectively respond to crises; maintain core functions when a crisis hits; and, informed by lessons learned during the crisis, reorganise if conditions require it." 29 
people, equity, efficiency, and resilient health systems. The overall framework explicitly recognizes that PHC systems lie within wider political, cultural, demographic, and socioeconomic contexts that play a critical role in determining their success.

\section{HOW DO WE ASSESS PHC CARE DELIVERY SYSTEMS?}

After developing the conceptual framework, PHCPI partners identified a set of 25 key performance indicators - "Vital Signs" - from globally available data that could be used at the national level to assess the performance of PHC systems, identify gaps in need of improvement, and allow countries to benchmark themselves across their region, income peer group, or other relevant comparisons (Table 1). For example, the Vital Signs measure continuity of care in three vertical areas: antenatal care, childhood vaccination, and TB treatment. These indicators can be compared within and across countries to understand common challenges and positive outliers, as shown in Figure 3. This type of analysis shows both that continuity of care varies widely across countries, and that these three measures of continuity of care can vary widely within countries. The latter insight highlights the importance of strong PHC systems in providing a foundation for vertical programs to build upon in order to provide continuity for all users of the healthcare system, not just some.
The PHCPI Vital Signs indicate that much work is needed to strengthen PHC measurement across LMIC. Data availability is a clear problem: of 135 LMIC, only one-Uganda - has data available for all 25 Vital Signs. Furthermore, many subdomains of the PHCPI Conceptual Framework, particularly within the Service Delivery domain, are not represented by any Vital Signs, reflecting a lack of accepted, reliable, and globally comparable indicators for measuring the core functions of a primary health care system.

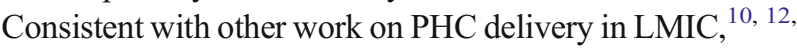
${ }^{23}$ the Vital Signs also demonstrate that performance across most domains is weak in many LMIC, suggesting ample targets for improvement in order to meet the Sustainable Development Goals.

\section{NEXT STEPS}

At its core, the PHCPI framework is an explication of the relationship between common global health areas of focussuch as accessibility and availability of services - and Starfield's classic primary health care functions. ${ }^{20}$ An emerging body of work suggests that these functions resonate in both low- and high-income country settings. ${ }^{24}$ Focusing health system development on the production of these functions in LMIC settings (as opposed to simply meeting input targets) is critical for accelerating improvement in primary health care

Table 1 PHCPI Framework with Key Questions for Managers, Policymakers, and Implementers

\begin{tabular}{|c|c|c|}
\hline$\overline{\text { DOMAIN }}$ & SUB-DOMAIN & KEY QUESTIONS \\
\hline A. SYSTEM & A1. Governance and Leadership & $\begin{array}{l}\text { Do national policies reflect the importance of PHC, promote high standards, } \\
\text { and involve stakeholders from all sectors? }\end{array}$ \\
\hline A. SYSTEM & A2. Health Financing & $\begin{array}{l}\text { Is primary health care adequately funded to ensure access, provide protection } \\
\text { against catastrophic expenditures, and ensure equitable use of resources? }\end{array}$ \\
\hline A. SYSTEM & $\begin{array}{l}\text { A3. Adjustment to Population } \\
\text { Health Needs }\end{array}$ & $\begin{array}{l}\text { Is the delivery of PHC flexible enough to adjust to and best serve the needs } \\
\text { of the population? }\end{array}$ \\
\hline B. INPUTS & B1. Drugs \& Supplies & Are essential drugs, vaccines, consumables, and equipment available when needed? \\
\hline B. INPUTS & B2. Facility Infrastructure & $\begin{array}{l}\text { Are there enough health facilities to serve the population, and are they appropriately } \\
\text { distributed? }\end{array}$ \\
\hline B. INPUTS & B3. Information Systems & $\begin{array}{l}\text { Are health facilities appropriately linked to information systems, including } \\
\text { system hardware and records? }\end{array}$ \\
\hline B. INPUTS & B4. Workforce & Is there sufficient staff and an appropriate combination of skills in PHC services? \\
\hline B. INPUTS & B5. Funds & $\begin{array}{l}\text { Are there sufficient funds available at the facility level to cover recurrent and fixed } \\
\text { costs? }\end{array}$ \\
\hline $\begin{array}{l}\text { C. SERVICE } \\
\text { DELIVERY }\end{array}$ & $\begin{array}{l}\text { C1. Population Health } \\
\text { Management }\end{array}$ & $\begin{array}{l}\text { Are local populations engaged in the design and delivery of health services to ensure } \\
\text { that their needs and priorities are met? }\end{array}$ \\
\hline C. SERVICE & C2. Facility Organization and & Are PHC facilities organized and managed to promote team-based care provision, \\
\hline DELIVERY & Management & $\begin{array}{l}\text { use of information systems, support staff, and performance measurement } \\
\text { and management to drive continuous improvement? }\end{array}$ \\
\hline $\begin{array}{l}\text { C. SERVICE } \\
\text { DELIVERY }\end{array}$ & C3. Access & Do patients have financial, geographic, and timely access to PHC facilities? \\
\hline C. SERVICE & C4. Availability of Effective & Are the staff of primary care facilities present and competent, and motivated \\
\hline DELIVERY & PHC Services & to provide safe and respectful care? \\
\hline $\begin{array}{l}\text { C. SERVICE } \\
\text { DELIVERY }\end{array}$ & $\begin{array}{l}\text { C5. High-Quality Primary } \\
\text { Health Care }\end{array}$ & Are PHC services high quality, meeting peoples' needs, and connected to other \\
\hline $\begin{array}{l}\text { DELIVERY } \\
\text { D. OUTPUTS }\end{array}$ & $\begin{array}{l}\text { Health Care } \\
\text { D1. Effective Service Coverage }\end{array}$ & parts of the health system? \\
\hline E. OUTCOMES & E1. Health Status & $\begin{array}{l}\text { Does the PHC system offer high-quality services across the lifespan? } \\
\text { Does PHC reduce the number of deaths and improve health? }\end{array}$ \\
\hline E. OUTCOMES & E2. Responsiveness to people & Does the PHC system respond quickly to the needs of the population? \\
\hline E. OUTCOMES & E3. Equity & $\begin{array}{l}\text { Are health outcomes equitably distributed across society, by geography, } \\
\text { education, and occupation? }\end{array}$ \\
\hline E. OUTCOMES & E4. Efficiency & Are resources used optimally to improve health outcomes? \\
\hline E. OUTCOMES & E5. Resilience of Health Systems & $\begin{array}{l}\text { Is the PHC system able to continuously deliver health care, regardless } \\
\text { of political or environmental instability? }\end{array}$ \\
\hline
\end{tabular}




\section{Afghanistan $\otimes$ Botswana $\otimes$ Burkina Faso $\otimes$ Cameroon $\otimes$ Guatemala}

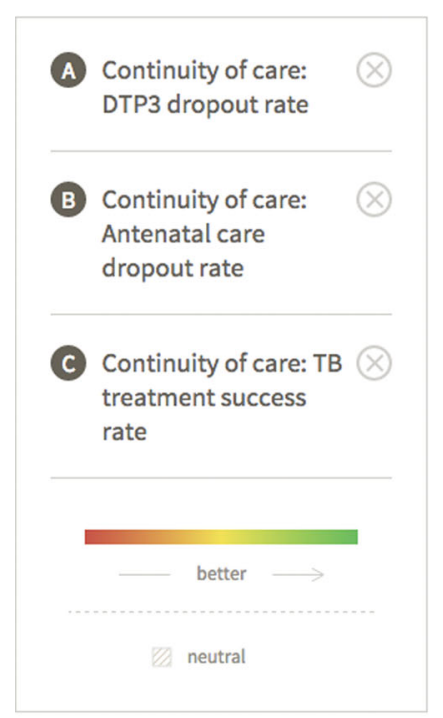

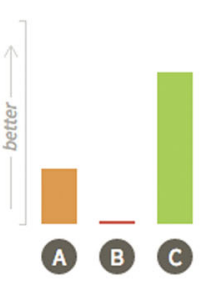

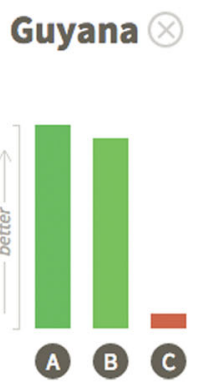

Pakistan

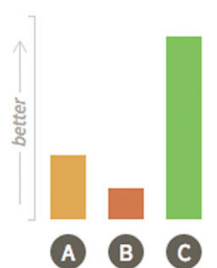

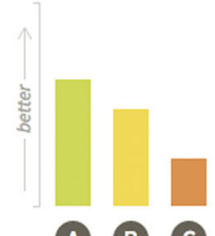

A B C

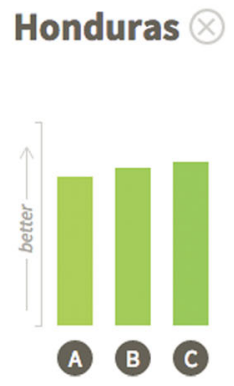

Sierra Leone

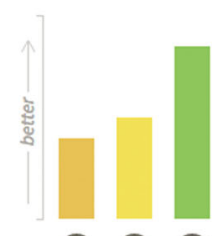

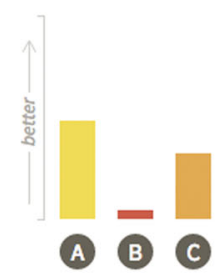
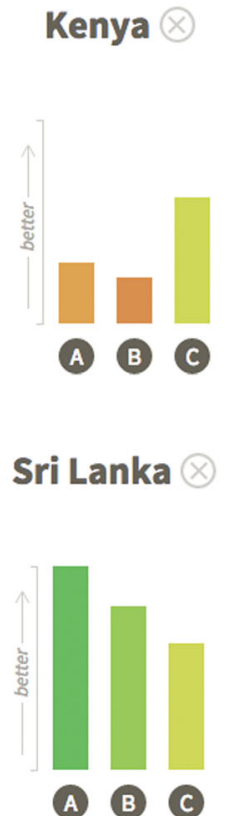

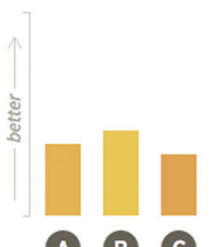

Liberia

Nigeria
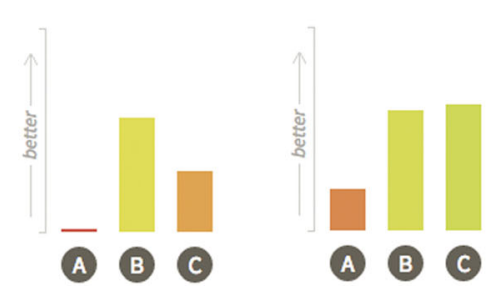

Vietnam

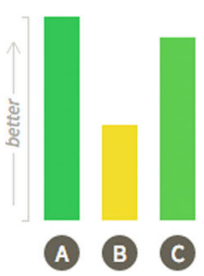

Figure 3 Data from PHCPI Vital Signs Indicators showing wide variety within and between countries in delivering continuity of care for children (immunization), women (antenatal care), and those with infectious diseases (tuberculosis). The height of the bars indicates a country's performance on each indicator relative to all other low- and middle-income countries. The diphtheria-tetanus-pertussis $(D T P)$ dropout rate is the percentage of children who do not receive three doses of DTP after receiving an initial dose. The antenatal care (ANC) dropout rate reflects the difference in the percentage of women who do not receive four ANC visits after receiving an initial visit. The tuberculosis (TB) treatment success rate is the percentage of all TB cases with successful completion of treatment. Data available at http://www.phcperformanceinitiative. org/tools/compare-tool\#?ind $=\& l o c=$.

and moving from vertical programming toward integrated health systems.

This lens of primary care functions provides the opportunity for shared learning between health systems in various stages of development. For example, high-performing primary care systems in high-income countries feature core components of effective management and team-based models of delivery such as proactive population management and risk-stratified care management. ${ }^{25}$ These features can be targeted in countries with transitioning burdens of disease that require a strong focus on chronic disease management and patient/ community engagement. Similarly, high-income countries can learn from successful examples of LMIC PHC models that feature deep community participation and engagement using community health worker models to reduce burdens of disease in an efficient manner. ${ }^{26}$ For example, Brazil's Family Health teams and Costa Rica's EBAIS model highlight the utility of using multidisciplinary teams, including community health workers, to improve health outcomes equitably. In
Estonia and Cuba, a focus on increasing access to care through a better trained and widely distributed PHC workforce ensures that primary health care is the first point of contact, while Turkey and Thailand highlight the benefits of reformed financing mechanisms to ensure consistent universal financial coverage for PHC. PHCPI is profiling innovative and successful strategies such as these to build a repository of "Promising Practices" for improving PHC performance. ${ }^{3}$ These bright spots of PHC provide useful lessons to countries as they embark on the path toward achieving universal health coverage. PHCPI is also working with a set of interested countries to catalyze PHC development efforts by making data on existing performance more available and useful at local levels, and linking it to a set of proven improvement pathways.

As all countries increasingly grapple with the challenges of providing high-quality, people-centered services at an affordable cost, primary health care is becoming a shared common focus. We present a framework for defined, detailed, and measurable primary health care performance that can be used 
by stakeholders at the global, national, and local levels to drive iterative improvement. Though the contexts within which they are produced vary widely, we propose that core functions of primary health care are universal across the world. The extent to which a health system produces services that are accessible at the point of first contact, continuous, coordinated, comprehensive, and people-centered is directly linked to the ability to produce intended outcomes. Successful progress requires sustained leadership focus and investment in measuring these key PHC domains, and making this data transparent and relevant particularly at the front lines of service delivery. Countries have an opportunity and a responsibility to go beyond antiquated notions of "levels" of care, simplified packages of care, or overly broad but under-defined concepts of primary health care, to move toward comprehensive, coordinated care that puts people and their needs at the center.

Acknowledgments: Funding for the Primary Health Care Performance Initiative is provided by the Bill \&. Melinda Gates Foundation. We acknowledge current and past members of the PHCPI working group for all of their efforts in moving the work forward, as well as the many stakeholders consulted in the development of the initiative so far.

Corresponding Author: Asaf Bitton, MD MPH; Ariadne LabsBrigham and Women's Hospital and the Harvard T.H. Chan School of Public Health, 401 Park Drive, Third Floor East, Boston, MA 02215, USA (e-mail: abitton@partners.org).

\section{Compliance with Ethical Standards:}

Conflict of Interest: The authors declare that they do not have a conflict of interest.

Open Access This article is distributed under the terms of the Creative Commons Attribution 4.0 International License (http:// creativecommons.org/licenses/by/4.0/), which permits unrestricted use, distribution, and reproduction in any medium, provided you give appropriate credit to the original author(s) and the source, provide a link to the Creative Commons license, and indicate if changes were made.

\section{REFERENCES}

1. Frenk J. Reinventing primary health care: the need for systems integration. Lancet. Elsevier Ltd; 2009;374(9684):170-3.

2. Cueto M. The origins of primary health care and selective primary health care. Am J Public Health. 2004;94(11): 1864-74.

3. Primary Health Care Performance Initiative. Primary Health Care Performance Initiative [Internet]. [cited 2016 Sep 19]. Available from: http:// www.phcperformanceinitiative.org/.

4. United Nations. Goal 3: Ensure healthy lives and promote well-being for all at all ages [Internet]. [cited 2016 Sep 19]. Available from: http://www.un. org/sustainabledevelopment/health/.

5. World Health Organization. Maternal Mortality [Internet]. [cited 2016 Sep 19]. Available from: http://www.who.int/mediacentre/factsheets/fs348/ en/.

6. United Nations Development Programme. Sustainable Development Goals [Internet]. [cited 2016 Sep 19]. Available from: http://www.undp.org/ content/undp/en/home/sustainable-development-goals.html.
7. Macinko J, Starfield B, Erinosho T. The impact of primary healthcare on population health in low-and middle-income countries. J Ambul Care Manage. 2009;32(2):150-71.

8. Kruk ME, Porignon D, Rockers PC, Van Lerberghe W. The contribution of primary care to health and health systems in low- and middle-income countries: a critical review of major primary care initiatives. Soc Sci Med. Elsevier Ltd; 2010;70(6):904-11.

9. Kringos DS, Boerma W, van der Zee J, Groenewegen P. Europe's strong primary care systems are linked to better population health but also to higher health spending. Health Aff. 2013;32(4):686-94.

10. Ly J, Sathananthan V, Griffiths T, Kanjee Z, Kenny A, Gordon N, et al. Facility-based delivery during the ebola virus disease epidemic in Rural Liberia: analysis from a cross-sectional, population-based household survey. PLoS Med. 2016;13(8):1-17.

11. Das J, Hammer $\mathbf{J}$, Leonard $\mathbf{K}$. The quality of medical advice in lowincome countries. J Econ Perspect. 2008;22(2):93-114.

12. Das J, Hammer J. Quality of primary care in low-income countries: facts and economics. Annu Rev Econ. 2014;6(1):525-53.

13. Sylvia S, Shi $\mathbf{Y}$, Xue H, Tian $\mathbf{X}$, Wang $\mathbf{H}$, Liu $\mathbf{3}$, et al. Survey using incognito standardized patients shows poor quality care in China's rural clinics. Health Policy Plan. 2014;1-12.

14. Hansen PM, Peters DH, Edward A, Gupta S, Arur A, Niayesh H, et al. Determinants of primary care service quality in Afghanistan. Int $\mathrm{J}$ Qual Health Care. 2008;20(6):375-83.

15. Primary Health Care Performance Initiative Methodology Note [Internet]. 2015 [cited 2016 Sep 19]. Available from: http://phcperformanceinitiative. org/sites/default/files/PHCPI Methodology Note_0.pdf.

16. WHO. Everybody's business: Strengthening Health Systems to improve health outcomes. WHO's Framework for Action. [Internet]. 2007 [cited 2016 Sep 19]. p. 1-56. Available from: http://www.who.int/healthsystems/strategy/everybodys_business.pdf.

17. Roberts MJ, Hsiao W, Berman P, Reich MR. Getting Health Reform Right. Oxford University Press; 2002.

18. Geiger HJ. Community-oriented primary care: a path to community development. Am J Public Health. 2002;92(11):1713-6.

19. World Health Organization. WHO global strategy on people-centred and integrated health services. Interim Report [Internet]. 2015 [cited 2016 Sep 19]. Available from: http://www.who.int/servicedeliverysafety/areas/people-centred-care/en/.

20. Starfield B. Is primary care essential? Lancet. 1994;344:1129-33.

21. World Health Organization, International Bank for Reconstruction and Development/The World Bank. Monitoring progress towards universal health coverage at country and global levels. 2014.

22. World Health Organization. Global Reference List of 100 Core Indicators. 2015.

23. Lee E, Madhavan S, Bauhoff S. Levels and variations in the quality of facility- based antenatal care in Kenya: evidence from the 2010 service provision assessment. Health Policy Plan. 2016;31(6):777-84.

24. Shi L. The impact of primary care: a focused review. Scientifica (Cairo). 2012;2012:432892.

25. Sinsky C, Willard-Grace R, Schutzbank A, Sinsky T, Margolius D, Bodenheimer T. In search of joy in practice: a report of 23 high functioning primary care practices. Ann Fam Med. 2013;11(3):272-8.

26. Crisp N. Turning the world upside down- the search for global health in the 21st century. 2010.

27. Kindig D, Stoddart G. What is population health? Am J Public Health. 2003;93(3):380-3.

28. O'Mara-Eves A, Brunton G, McDaid D, Oliver S, Kavanagh J, Jamal F, et al. Community engagement to reduce inequalities in health: a systematic review, meta-analysis and economic analysis. Public Health Res. 2013;1(2).

29. Kruk ME, Myers M, Varpilah ST, Dahn BT. What is a resilient health system? Lessons from Ebola. Lancet. Elsevier Ltd; 2015;385(9980):1910-2 